Yayınlayan: Ankara Üniversitesi KASAUM

Adres: Kadın Sorunları Araştırma ve Uygulama Merkezi, Cebeci 06590 Ankara

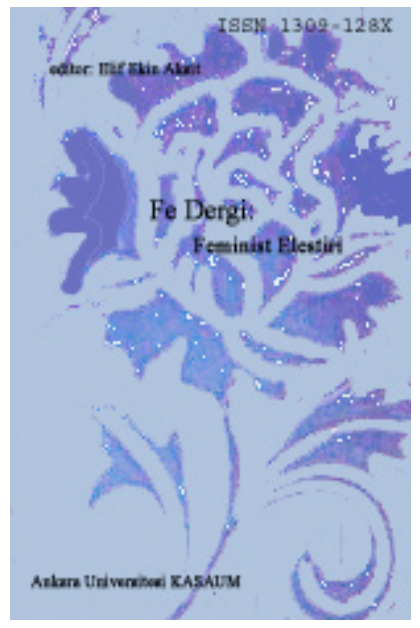

Fe Dergi: Feminist Eleştiri 13, Sayı 2

Erişim bilgileri, makale sunumu ve ayrıntılar için:

http://cins.ankara.edu.tr/

Siborg'lar, Yoldaş Türler ve Başka Yerler: Haraway'ın Spekülatif Masallaştırmalarında Dönüşüm Arayışı

Ece Öztan

Çevrimiçi yayına başlama tarihi: 15 Aralık 2021

Yazı Gönderim Tarihi: 10.05 .2021

Yazı Kabul Tarihi: 01.12.2021

Bu makaleyi alıntılamak için: Ece Öztan, "Siborg'lar, Yoldaş Türler ve Başka Yerler: Haraway'ın Spekülatif Masallaştırmalarında Dönüşüm Arayıșı" Fe Dergi 14, no. 2 (2021), 26-32.

URL: http://cins.ankara.edu.tr/26_3.pdf

$\mathrm{Bu}$ eser akademik faaliyetlerde ve referans verilerek kullanılabilir. Hiçbir şekilde izin alınmaksızın çoğaltılamaz. 


\section{Siborg’lar, Yoldaş Türler ve Başka Yerler: Haraway'ın Spekülatif Masallaştırmalarında Dönüşüm Arayışı Ece Öztan*}

Bu yazı feminizm, ütopyalar, insan sonrası ve toplumsal cinsiyet sonrası bir özne araylşına ilişkin düşünsel bir patikanın izini sürmeye çalışlyor. Donna Haraway'ın Siborg Manifestosu'ndan Chutulasen'e uzanan yolda geliştirdiği figürlerin, pandeminin orta yerinde iyi bir hayat tahayyülüne ilişkin olanaklarına değiniyor. Bu çerçevede, doğa/kültür, biyolojik-teknolojik, fiziksel olan olmayan, insan-hayvan ikilemine düşmeden özcü olmayan bir öznelliğin tanımlanması konusunda Haraway'ın sunduğu çerçeveyi gözden geçiriyor. Siborg Manifestosu'ndan itibaren Haraway'ın önümüze koyduğu siborg, yoldaş türler, spekülatif masallaştırmalar, Khtulusen gibi figür ve nosyonlara; ekolojik yıkım, pandemi, derinleşen eşitsizlikler içerisinden bakmaya çalışıyor

\section{Anahtar Kelimeler: Donna Haraway, posthuman, Chthulucene, COVID-19, spekülatif} masallaştırmalar

Cyborgs, Companion Species and "Other Places": The Alchemy in Haraway's Speculative Fabulation

Haraway's quest for "another place" is a rich ground to "go home" and become distant from "closed" space. This article seeks to track the path to pursuit of post-human and post-gender subject in feminist and utopian visions. From the Cyborg Manifesto to Chutulecene, Haraway's figures and notions are being examined regarding the imagination of "a good life" in the midst of the pandemic. In this context, the article reviews Haraway's framework for defining a non-essentialist subjectivity without falling into the nature/culture, biological-technological, non-physical, human-animal dilemma. It deals with Haraway's figures and notions such as siborgs, companion species and speculative fabulations, Chthulucene through the ecological destruction, pandemic, and deepening inequalities.

Keywords: Donna Haraway, posthuman, Chthulucene, COVID-19, Speculative Fabulation

Giriş

"Dünyalı bir varlık olmanın temelinde birbiriyle zorunlu bir dayanışma yatar. Bu dayanışma, hiçbir
zaman sadece insanlar arasında değildir. Bu her zaman yerleşik sosyo-doğal ekolojilerde vuku bulur.
Çok hızlı bir örnek vereyim: şu anki virüs muhtemelen, hatta doğrudan bio çeşitliliğin süregiden
tahribatından, yarasalar dahil diğer canlı varlıkların yaşam sistemlerinin basite indirgenmesinden
kaynaklanıyor. İnsanların tarıma hızla artan kentleşmeye diğer varlıkların yaşama şekillerini nüfuz
etmeye dayalı yaşam biçiminin salgınlara yatkın bir dünya yarattı. Salgınları yatkın dünya şu anda bir
miktar kapıları çalsa da, zenginleri o kadar da etkilemiyor. Virüsler hakkında düşünmek tarımsal s
istemlere, salgına yatkın düzeneklere kafa yormayı ve onların salgınlara yatkınlığını azaltmayı da
gerektiriyor. Bizi ve diğer türleri felakete sürüklemeye eğilimli olmayan bir birlikte yaşam ve ölüm ş
ekli bulmalıyı. Şu anda tam da bu türden bir düşünme biçimine ihtiyaç var. Bu kıyamet tellallığı
yapmak değil. Ancak kitlesel ölümlere ciddiye alan bir düşünme biçimi." 1

Donna J. Haraway, Torino Kitap Fuarl, 14 Mayıs 2020

Donna Haraway, Belayla Kalmak (Staying with Trouble) adlı son kitabında, başka türlerle beraber iyi yaşamaktan ve ölmekten bahsediyordu. Pandemi döneminin ve kapanmaların başlangıcında gerçekleştirilen bu söyleşide Haraway, mevcut durumda birbirimizle dayanışmanın daha önce hiç olmadığı kadar yoğun bir gereklilik haline geldiğini ancak bu dayanışmanın sürdürülmesi ve yaygınlaştırılmasının pandemi koşulları nedeniyle güçleştiğini ifade ediyor. Ancak dayanışmanın şu anda seçenek değil bir zorunluluk olduğunun israrla altını çiziyor. Kısa değil uzun dönemli bir dayanışma üstelik.

*Dr. Siyaset Bilimi, ece.oztan@gmail.com , Yazı Gönderim Tarihi: 10.05.2021, Yazı Kabul Tarihi: 01.12.2021 
Haraway’ın "başka yer" arayışı, yaşadığımız "yere” batmış ve kapatılmışlığımızla biraz olsun mesafelenmek ve yurtsuzlaşmak için zengin bir uğrak. Yalnızca siyaset ikliminde değil düşünsel dünyamızda da iyice uzaklaştığımız diyalog ve bağ kurmanın imkanları üzerine düşünmek sağaltıcı. Bu yazıda, Haraway’in ütopyacı düşünce, insan sonrası ve toplumsal cinsiyet sonrası bir özne arayışına ilişkin düşünsel patikasının ve bu patikanın pandeminin orta yerinde iyi bir hayat tahayyülüne ilişkin olanaklarının izini sürmeye çalışacağım. $\mathrm{Bu}$ çerçevede, doğa/kültür, biyolojik-teknolojik, fiziksel olan olmayan, insan-hayvan ikilemine düşmeden özcü olmayan bir öznelliğin tanımlanması konusunda Haraway'ın sunduğu çerçeveyi gözden geçirerek; Siborg Manifestosu'ndan itibaren Haraway'ın önümüze koyduğu siborg, yoldaş türler, spekülatif masallaştırmalar, Chutulecene gibi nosyonlara; ekolojik yıkım, pandemi, derinleşen eşitsizlikler içerisinden bakmaya çalışacağım.

\section{Spekülatif kurmacalar ve "başka yerler"}

1970’ler sonrasında ütopya geleneğindeki kırılmalar, tarihin sonu tezlerine paralel olarak, ütopyaların sonu algıs1 da yaratmıştır. Diğer yandan, iyi bir dünya umudunun azalması ya da kötümserliğin bir yansıması olarak da değerlendirilmiştir bu düşüş. İşte Donna Haraway’ın Siborg Manifestosu² (Haraway 1985) tam da bu dönemde yayımlanan, ütopyacı bir vizyon içeren önemli bir metin. Manifesto, dönemin özneyi, teoriyi ve siyaseti düşünme yolunda açtığı yeni patikalarla; teknobilim, neoliberalizm ve yeni sağın kasvet yaydığı bir dönemde, imkanları düşünmeye davet ediyor.

Kuşkusuz Haraway yaklaşık kırk yıldır farklı disiplinlerde çok çeşitli yönleri ile tartışılan çalışmalar üretti. Türkçede, Haraway'in farklı alanlarda tartışılan, ilham veren bir yazar olarak tanınmasına neden olan meşhur Siborg Manifestosu dışında 2010 yılına kadar hiçbir çalışması yayımlanmamıştı. Nihayet 2010'da, Socialist Review'da 1985 'te yayımlanan Siborg Manifestosu da dahil olmak üzere, yazarın düşüncesinin temel uğraklarını öne çıkaran kimi önemli metinlerinden oluşan bir Donna Haraway seçkisi Metis Yayınları tarafından Başka Yer adıyla yayımlandı (Haraway 2010). 2020'de ise, Haraway'ın düşünsel izleği ve metodolojik zenginliğinin yanı sıra; özel yaşamı, akademi ve öğrencileriyle ilişkisinden eylemciliğine varana dek yaşamının farklı yönlerine dair ufuk açıcı bir söyleşi olan Tıpkı Bir Yaprak Gibi yayımlandı. ${ }^{3}$ Kuşkusuz Haraway’ın oldukça zengin düşünsel izleğinin kapsamlı bir analizini yapmak bu yazının kapsamını aşan bir çaba olurdu. Buradaki sınırlı amacım Haraway’ın siborg, yoldaş türler, Chthulucene gibi nosyonların içerdiği dönüşüm çağrısı ve özne arayışını, pandemi döneminin içerisinden bir bakışla izleğini sürme ile sınırlı olacak.

\section{Canavarın karnından yazmak!}

"Yirminci yüzyılın sonlarına, bizim mitik zamanımıza gelindiğinde, hepimiz kimerayız, ${ }^{4}$ kurumsallaştırılmış ve imal edilmiş makine-organizma melezleriyiz; kısacası siborguz. Siborg bizim ontolojimiz; siborg bize politikamızı verir. Siborg her türlü tarihsel dönüşüm imkanını yapılandıran iki birleşik merkezin, yani hayal gücünün ve maddi gerçekliğin yoğunlaştırılmış bir imgesidir.” (Haraway 2010, 46).

Haraway, çeşitli vesilerle dile getirdiği gibi canavarın karnından yazmaktadır. Siborg figürü ${ }^{5}$ ve yazarın 1980'lerden itibaren çalışmalarında odaklandığ 1 primatlar, DişiAdam $\bigodot$, OnkoFare ${ }^{\mathrm{TM}}$, Ortho-mune*TM, yoldaş türler, köpek insan, mütevazi tanık, kompozitler gibi figürler dünyayı anlama yolumuza ilişkin hem disiplinlere ilişsin sınırlara hem de zihinsel ve kavramsal ikiliklere meydan okuyarak, başka bir yer tahayyülüne ve imkanlarına işaret ediyor.

Tüm bu imgeler, COVID-19 pandemisinin yol açtığı küresel kapanma döneminde daha da çarpıcı hale geliyor. Küresel patojen, hem insanlararası hem insan ve diğer türler arası, hem de canlı olan ile olmayan arası ilişki ve birlikteliklere dair pek çok şeyi bir arada düşünmeyi kaçınılmaz kılıyor. Biyoloji, epidemiyoloji, immünoloji ile sosyoloji, ekonomi ve siyaset arasındaki ayrımların dışına çıkarak düşünmeye zorluyor bizi. Pandemi süreci ağırlıklı olarak medikal terimlerle, sosyal alanda da daha çok spesifik bir ekonomi kavrayışından ele alınıyor. Bu terminoloji COVID-19 ile mücadele pratiklerinde de belirleyici. Bu anlamda "fiziksel mesafe yerine "sosyal mesafenin", virüsle mücadelede ise "savaş" metaforunun kullanılması, doğa-insan ve insan-insan ilişkileri bakımından düşünme biçimimizin bir arada yaşama ve dayanışma tahayyül edebilecek patikaların dışında tezahür ettiğine örnek oluşturuyor. Giderek hayati halen gelen iyi hayat tahayyülünde Haraway'in imge ve metaforlarının güçlendirici bir potansiyeli var.

Siborg figürüne dönecek olursak; Haraway'ın kendi ifadesiyle siborg "muhalif ve ütopiktir, masumiyetten tamamen yoksundur. Kamusal-özel kutupluluğunca yaratılmamış olan siborg, kısmen oikos’taki, yani hanedeki toplumsal ilişkilere dair bir devrime dayanan teknolojik bir polis tanımlar" (Haraway 2010: s.48). 
Yapay zeka alanında varılan noktayı düşünürsek; nanoteknoloji, artırılmış gerçeklikler, implantlar ve akıllı her şeyin; organizmaya eklemlenebilir, dahası organizmayı dönüştürebilir bir evren oluşturduğunu düşünürsek, Siborg figürü günümüzde de çok çarpıcı bir imgedir.

Haraway, militarist teknolojinin siborg figürünü de biyokapitalin konusu olan melezlenmiş organizmaları da başka bir yerden yazmaktadır. Başta siborg olmak üzere bu figürlerin en etkileyici yanı, teknolojiyi ve bilimsel süreçleri tahakkümün olduğu kadar özgürleşmenin potansiyel araçları olarak tanımlamasıdır. Haraway'ın, Tıpkı Bir Yaprak Gibi başlıklı söyleşisinde bilim teknoloji ile ilgili olumsuzluğun bu alanların insan karşıtı bir alan olarak algılanmasına ilişkin köklü gelenek oluşturduğunu ifade eder (Goodeve 2020, 35). Haraway için bu aslında bilimsel pratiklerin tarihselleştirilmesi bakımından önemli bir sorundur.

Siborg, primat, genetiği değiştirilmiş ve patentlenmiş canlılar gibi figürler Haraway’in düşüncesinde hümanist özne ve ontolojiye yönelen temel bir eleştiri aracına dönüşür. Nihan Bozok, tüm bu feminist figürlerin umut ve korkuları, olasılıkları ve tehditleri, aydınlığı ve karanlığı bir arada konuk etmesine dikkat çekmektedir (Bozok 2019, 131). Bu figürler "feministtir; çünkü, feminist teori ve siyaset, cinsiyetin, sabitlenmiş organik beden anlatıları ve ilişsilerinden oluşan tahakküm enformatiğine karşı çıkarlar. Bu bir anlamda bedenden ve konumlanmışlıklardan yola çıkarak genişleyen bir arayıştır. Braidotti'nin ifadesiyle; "gözden çıkarılabilir bedenlere sahip, insandan aşağı konuma indirgenen, cinsiyetlendirilmiş, irk üzerinden belirlenmiş ve doğal addedilmiş" ve "diğerlerinden daha ölümlü” tüm görmezden gelinenlere ilişkin bir bakış açısıdır bu (Braidotti 2018, 28).

Braidotti, hümanizm mirasıyla başa çıkmak için daha fazla etik sorumluluğa ihtiyacımız olduğunu ifade ederken, insansonrası (posthuman) düşüşünü üstlenebilecek bir özne kuramı arayışındadır. Bu düzlemde Haraway'i da hümanizm sonrası jeneolojik çizgide değerlendirmektedir. ${ }^{6}$ Braidotti, posthuman kavramını kullanırken, Haraway posthuman/ism adlandırmasını kullanmaktan imtina etmektedir. Haraway bir röportajında posthumanizmi, özellikle transhumanist tekno-gelişim öyküsünün, teleolojik, evrimsel bir aşamasına dönüştürülme riski nedeniyle kullanmaktan yana olmadığını belirtiyor (Gane 2006). Bu vurgu farkı büyük ölçüde Braidotti'nin sömürgecilik, Nazizm, göçmen ve mülteci karşıtlığı, yabancı düşmanlığı ve neoliberal piyasa ekonomisinin Avrupa deneyimi ile Avrupa merkezli özne ve hümanizmine karşı konuşurken; Haraway’ın teknobiokapitalin, yaşamın kendisinin metalaşması ve markalaşmasının, militarist teknobilimin, zenginliğin hiper-kapitalist birikiminin, küresel bilgi-eğlence aygıtının içinden, yani ABD bağlamında konuşmasından kaynaklanmaktadır. Haraway, doğanın ve kültürün tek kelime olduğu doğa-kültürün içinde yaşamaktan bahsederken; genin kültürel fetiş olarak tanımlanması, sermaye-teknobilim ilişkisi, yerli ve yerel bilginin kültüre indirgenmesi, iklim değişikliği, biyolojik çeşitlilik kaybı, toksik kimyasallar ve su kaynaklarının ve diğer fiziksel kaynakların tükenmesi gibi "hikayelere" odaklanır. Haraway için tüm bu hikayeler; nesnelerin, bilim pratiklerinin yani bu doğa-kültürün içindedir.

\section{Spekülatif masallaştırmalar}

Haraway’ın ütopyacı vizyonu, tam da bu konumdan başka yere bakış serüveninde yatar. Bir başka deyişle, canavarın karnında başka bir hikâye anlatma, başka bir figürasyon, başka bir mitik figür arama çabası içerisindedir. Aksu Bora, Haraway’ın ilk olarak Siborg figüründe karşımıza çıkardığı bu ütopyacı çabayı "insan olmayana doğru açılan, genişleyen bir dünya" olarak betimliyor (Bora 2018, 206). Ütopyacı vizyonu kabul etmekle birlikte Haraway, Siborg Manifestosu'nda özellikle bilimkurguya atıfta bulunarak "bilimkurgu ile toplumsal gerçeklik arasındaki sınırın bir göz yanılgısından ibaret olduğunu söylüyor.” (Haraway 2010, 46) İroni, mecaz, mitik figür, kurgu gibi adlandırmaların ötesinde Haraway daha sonraki çalışmalarında, bu arayışını yine dilin sınırlarını ve ironisini kullanarak genellikle bilimkurgunun kısaltması olarak kullanılan SF'yi (science fiction) "spekülatif masallaştırma" (speculative fabulation) olarak kullanır. Spekülatif masallaştırmayı, dilden dile aktarılan hikayeler ve hikaye anlatıcılığı ile bağlantılandırarak; başka yer arayışına ilişkin kolektif ve ilişkisel bir hikayeleme yöntemi olarak görür.

Haraway, "Bilimkurgu, Spekülatif Masallaştırma, Sicim Figürleri” başlıklı konuşmasında spekülatif masallaştırmayı bilinçli olarak bilim kurgu, bilim gerçeği, bilim fantezisi gibi bir dizi figür olarak materyal ve semiyotik bir zenginlik potansiyeli taşıdığı için kullandığını ileri sürmektedir (Haraway 2013). Sanatçı Carolyn Christov Bakargiev, 14. İstanbul Bianeli açılış konuşmasında tam da Haraway’ın bu spekülatif kurmacalarının içerdiği potansiyele gönderme yaparak, birbirimize yeni hikayeler anlatabilmeye olanak veren, hayal gücünü kösteklemeyen, tahayyüle vurgu yapar (Bakargiev 2015). Bu hikayeleme, aslında Haraway’ın tanımlayıcı ve 
negatif bir etkinlik olarak eleştirelliğin ötesine geçen, üretken bir eleştirellik nosyonu ile de doğrudan bağlantılıdır. ${ }^{8}$

Haraway, Siborg Manifestosu'nda döneminin bilimkurgusuna uzunca bir yer ayırır. Haraway’a göre, "günümüz bilimkurgusu siborglarla, aynı anda hem hayvan hem de makine olup doğal mı olduğu yoksa insan elinden mi çıktığ 1 muğlak dünyaları mesken tutan yaratıklarla doludur.” (Haraway 2010, 46) Haraway, feminist bilimkurgunun renkli urktan kadınlar ve ucube benlikleri inşa ederken, siborg mitinin oluşturulmasına önemli katkılar yaptığını vurgular (Haraway 2010,80). Farklı katmanları ile okunabilecek bir metin olan Siborg Manifestosu'nda Haraway, feminist bilimkurgunun dişında feminist teori ile de konuşur. Bu konuşma metnin bütününe yayılmıştır. Luce Irigaray'dan, Monique Wittig'e; Amerikan radikal feministlerinden, Julia Kristeva ve Catherine MacKinnon'a çok farklı feminizmlerle diyaloğa girmektedir. Haraway’ın düşüncesinin izini farklı metinlerinde sürdügüumüzde, bu diyalog ve eklemlenmenin yalnızca Marksizm, feminizm, biyoloji, edebiyat, bilimkurgu, bilim tarihi alanlarından değil; eleştirel ırk kuramları, ekofeminizm ve politik ekoloji, postkolonyalizm, kuir kuram, posthümanizm gibi farklı alanlardan beslendiğini söylemek mümkün.

Haraway, siborg figürünü kullanırken, özellikle renkli ırktan kadınlara ve deneyimleri ikincilleştirilen kadınlara vurgu yapar. Sosyalist-feminist bir arayış ile Haraway, hem sınıf hem de cinsiyetle sabitlenmiş öznelere karşı çağının gelişmeleri çerçevesinde yeni düşünce patikaları açar. Siborg Manifestosu ile ortaya konulan ontolojinin önemli bir yönü, bilim insanlarının nesneleri ile ilişkilerini nasıl algılayacakları ve nasıl bir duyarlılık ile ilişkilenecekleri meselesidir. Haraway’ın bilimsel konumluluğa ve tanıklığa ilişsin kavrayışı hem doğal-kültürel dünyaya ilişkin bir anlama biçimi hem de eyleme biçimidir. Haraway mütavazi tanıklığı, "bilimin inanılır, medeni erkeğinin 'laboratuvar'ında bir özne konumuna yerleşmeyen ya da yerleşemeyenlerin ihtiyaçlarını gözeten araştırmalar” yapan bir figür olarak tanımlamaktadır (Goodeve 2020, 174).

\section{Yeraltundan başka yere}

Haraway’ın son çalışmalarında oluşturduğu bir diğer kurgu, antroposen çağı adlandırmasına ve nosyonuna alternatif, bu nosyonu açan, genişleten ve karmaşıklaştıran Chthulucene kurgusudur. Antroposen ${ }^{9}$, Yunanca insan anlamına gelen antropos’tan türetilen ve içine girdiğimiz yeni bir jeolojik çă̆ın adı olarak kullanılan bir kavram. Bu adlandırma özellikle küresel ısınma, iklim değişikliği, ekolojik tahribatlar nedeniyle yapılan yeni bir tanımlama. Haraway, antroposen yerine bir süre, bu kavramı, ekolojik tahribatın sorumluluğunu kapitalist piyasa ilişkilerinde arayan kapitalosen ${ }^{10}$ kavramını tercih etmişse de sonradan, yoldaş türler, siborg gibi mitik kurgularında başvurduğu yeni bir dil ve hikaye oluşturma motivasyonuile Chthulucene kavramını benimsemiştir (Haraway 2015).

Bir başka ifadeyle Haraway yeni dönemi, tümüyle özel bir anlatı merceği ve olası anlamların karmaşık bir örüntüsü ile yeniden tasarlar. Korku edebiyatının kült isimlerinden H. P. Lovecraft'ın 1928'de yazdığı 'The Call of Cthulhu' adlı bilim kurgu hikayesindeki" ${ }^{11}$ kabus figürü olan "Cthulhu”nun yazılışını da "Chthulu"ya dönüştürerek, yeni bir mitik kurgu oluşturur. Kozmik korku edebiyatının önde gelen isimlerinden Lovecraft'ın alenen ırkçı ve kadın düşmanı figürünü bir harf değişikliğiyle kullanmak, Haraway’ın teknobilimin, genetik teknolojilerinin tam içinden giriştiği mütavazi tanıklık nosyonu ile ilişkilidir. Haraway, bu figürü yeni hikayeler anlatmak, hikayelerle bağ kurmak için özellikle kullanır. Chthulucene, mitolojide yer altında yaşayan tanrıların yeri anlamında "chthonic" sıfatı ile de ilişkilidir. Lovecraft'ın hikayesinde aslında Ctulhu yeraltı güçleri ile ilgilidir. Haraway'ın bu kurguyu bir korku hikayesinden alması tesadüf değil; çünkü "tam şu anda yeryüzü sığınağı olmayan, insan ve insan olmayan sığınmacilarla dolu”dur. (Haraway 2015: 160). Bu anlamda Haraway'ın metni insan-doğa, insan- insan olmayan, insan-hayvan gibi ikiliklere karşı bir türlerin birbiri ile akraba olduğu bir türlerarası eşitlik düzeni tahayyülüdür. Ferwerdana, Chthulucene’i Haraway'ın yeni manifestosu olarak görmektedir (Ferwerdana 2016, 38).

Haraway, türlerin birbiri ile akraba olduğu bir tahayyül ile doğa-kültür, insan ve insan olmayan, insanhayvan ve insan-makine gibi ikilikler arasındaki sınırları aşındırarak ikili sistemleri sorgulamaktadır. Çelik, Haraway’ın teknolojik yeniliklere duyduğu heyecanının giderek bu dünya güçlerinden duyduğu heyecanla yer değiştirmeye başladığını ifade eder (Çelik 2018, 34). Gerçekten de ekolojik yıkım ve tehditler karşısında Haraway'ın ütopyacı vizyonunun insan olmayanlara ilişkin sorumluluğun yakıcılığını vurgulamak için başka bir melezlenmeye ve birlikte oluşturmaya kaydığını söyleyebiliriz. Haraway 2016' da yayımlanan "Belayla Kalmak" kitabında, insan soyundan gelenlerin gelecekte biyolojik yeniden üretim yerine insanlar hayvanlar ve diğer insan olmayanlar arasında akrabalık kurma biçimleri geliştirerek, hayatta kalabildikleri üzerine birçok nesli içeren 
Camille Öyküleri kurgusuna başvurmuştur (Haraway 2016a). 2025 ile 2425 arasında geçen her bir Camille öyküsünde; siyasal ve ekolojik hatalar yapılmakta ve her bir öykü okuyucuyu öykülerdeki mücadelelere eklemektedir. Bu anlamda Haraway'ın eleştirel ütopya vizyonu, tam da bu bitmemişlik, tamamlanmamışlık, köklerini hayatın ve deneyimlerin kendisinden, praksisten alan bir dönüştürme gücü içerir.

Haraway, Chthulucene ile ilgili olarak bu gezegen için sorumluluklar temelinde ahlaki ve siyasal muhakemeleri tahayyül etmek ve pratik etmek anlamında worlding yani, "dünyevileşmek/dünyasallaşmak" kelimesini kullanmaktadır. Haraway İngilizce’de Naga, Gaia, Tangaroa, Medusa, Spider Women gibi bilim kurgu alanındaki binlerce isimlendirmeyi, Lovecraft'ın asla tahayyül edemeyeceği ve kucaklayamayacağı feminist, spekülatif masallaştırmalar olarak görür (Haraway 2015, 160). Haraway’ın mitik kurguları ve spekülatif masalları, politik olarak zenginleştirici ve ilham verici bir başka yer umudu olarak öne çıkıyor. Haraway'ın düşünsel izleğini, iyi bir yaşam üzerine yeniden düşünmeyi kaçınılmaz kılan pandemi deneyimlerimiz ile birlikte okumak çok çarpıcı.

\section{Sonuç}

COVID-19 pandemisinin; endüstriyel tarım ve hayvancılık ölçeğinin genişlemesi, Amazon Ormanları dahil yerkürenin tüm canlı alanlarında yıkıcı tahribatlar sonucunda güvenlik çemberi oluşturan doğal canlı yaşamın yok edilmesi ile doğrudan ilişkili olduğunu düşündüğümüzde, Haraway’ın mitik kurguları ve spekülatif masallarını dünyayı anlama ve yıkıcı olmayan bir yaşam pratiği açısından mütevazi bir tanıklığa çağrı olarak okumak gerekiyor. Haraway'ın “çoktürlü ekoadalet” (multispecies ecojustice) (Haraway 2015, 161) olarak ifade ettiği şey, sosyal adalet arayışının tüm yaşam biçimleri ve alanlarında izinin sürüldüğü bir tahayyül ortaya koymaktadir.

COVID-19 yalnızca insan-doğa, insan-hayvan-virüs etkileşimleri açısından değil, insanlar arası ilişki ve insan- makine etkileşimlerinin de dönüşümünü apaçık gözler önüne seriyor. Kimlerin hayatının virüsten nasıl etkilendiği, kimlerin hayatının riske atılabilir hayatlar olarak görüldüğüneilişkin tanıklık ve deneyimlerimiz bizi; yaşam bilimleri, immünoloji, istatistik ve politik ekonominin maddi-semiyotik ortaklığına dahil ediyor. Haraway’ın dünyevi olmak ve akrabalık gibi nosyonları, şu anda ve içinde yer aldığımız biyolojik, fizyolojik, ticari, teknolojik, genetik ve politik hikayeleri tanıklık ve sorumluluklar yoluyla değiştirmeye çağırıyor bizi. Bu nedenle son kitabının başlığı olan Belayla Kalmak, ahlaki bir sorumluluk alma alanını çarpıcı bir şekilde genişletiyor. Pandeminin dijital teknoloji dolayımının yoğunluğunu ve alanlarını olağanüstü artırdığı, pandemi kontrolü ve gözetiminin dijital uygulamalar, kişisel veri ve akıllı ağlar ile yürütüldüğü bir dönemde ${ }^{12}$, tüm bu dönüşüm olanaklarını sosyal adalet perspektifinden yeniden tahayyül etmeyi de içeriyor bu sorumluluk. Bu nedenle Haraway'ın insan ve insan dışı tüm yaşam ve makine alanları birlikte ortaya koyduğu dünyevi ontoloji, adalet kavramını; sosyal, biyolojik, genetik, politik ve teknolojik tüm yönleri ile yeniden düşünmek ve yeni dünyevi hikayeler yaratmak bakımından oldukça zihin açıcı. 
${ }^{1}$ Donna Haraway ile 14 Mayıs 2020'de Torino Kitap Fuarı'nda Belayla Kalmak (Staying with Trouble) adlı son kitabı üzerine yapılan çevrimiçi söyleşiden alınmıştır. https://www.birartibir.org/aidiyetler/748-dayanisma-secenek-degil-yukumluluk

${ }^{2}$ Siborg Manifestosu, Haraway'ın bir röportajında belirttiği gibi, ABD'de Reagan'ın seçilmesinden kısa bir süre sonra Socialist Review dergisinin yazardan, sosyalist feminizmin geleceği ile ilgili bir yazı kaleme almasının istenmesi sonrasında üretilen bir metin (Gane 2006,135). Haraway, manifestonun yazıldığı dönemde bir arada tutması imkansız ama aynı zamanda birlikte düşünülmesi gerekli şeyleri bir araya getirme yolunda çaresiz bir çabanın ürünü olduğunu ifade ediyor. "Benim için Siborg Manifestosu, savaşı ve savaşın ürünlerinin nasıl hatırlayacağımız ve eleştireceğimiz, ekofeminizm ve teknobilimi nasıl gerçekte biraraya getirilebileceği ve genel olarak zalim kökenlerden uzaklaşan olasılıkları nasıl ağırlayacağımızı düşünmeye çalışan Sosyalist Review için yazılan ağırbaşlı bir sosyalist-feminist bir beyandı.”(Haraway 2004, 3).

${ }^{3}$ Kitabın İngilizce baskıs1 "How Like a Leaf: An Inyerview with Donna J. Haraway" 2017 yılında yayımlanmıştı.

4"Yunan mitolojisinde ağzından ateş püsküren aslan başlı, keçi gövdeli ve yılan kuyruklu yaratık."-ç.n. (Haraway 2010, 46)

${ }^{5}$ Siborg kelimesi ilk kez 1960 'da N.A.S.A (National Aeronautics and Space) programında mühendis olarak çalışan Clynes ve Kline tarafından yazılan bir makalede, insanların uzay yolculuğunda ortama adaptosyonlarını mümkün kılacak makine ile melezlenmiş ve bedensel yetileri geliştirilmiş/dönüştürülmüş insan-makine bileşimlerini anlatmak için kullanılan "siber" ve "organizma" kelimelerinin birleşiminden oluşturulmuş bir kelimedir (Clynes ve Kline 1960, 30 Cook 2004, 2 içinde).

${ }^{6}$ Posthümanizm insanı, makinalar, hayvanlar ve yeryüzünden ontolojik olarak “üstün bir tür” olarak tanımlamayı reddetmektedir (Miah 2008, 72). İnsan ve insan olmayan arasındaki sınır hep akıcı olagelmiştir. Günümüzdeki teknolojik gelişmeler bunu yalnızca daha açık ve belirgin hale getirmiştir. Bu nedenle insansonrası perspektif, teknolojik gelişmelere iyimser ya da kötümser bir bakışı reddeder. Braidotti, posthümanizmin, hümanizim ve insan merkezcilik (anthropocentrism) eleştirileri kesişiminde ortaya çıkan çok farklı disiplin alanlarında yükselen non/in/trans/meta/posthuman söylemlerinin izini sürmeye olanak veren bir çerçeve olduğunu ifade etmektedir (Braidotti 2018, 6)

${ }^{7}$ Haraway bu konuşmayı, 2011'de Pilgrim ödülünü alırken yapmış, konuşma daha sonra yayımlanmıştır.

${ }^{8}$ Donna Haraway ile söyleşisinde Thyrza Nicholas Goodeve de, hocası Haraway'ın kritiklik nosyonun geleneksel eleştirel düşünce geleneği ile çarpıcı bir farklılık taşıdığına vurgu yapmaktadır. (Goodeve 2020, 124-125).

${ }^{9}$ Antroposen terimi 2000 yllında jeolog Crutzen ve Stoermer "atmosfer ve yerküreye insan etkinliklerinin artan etkisi”" nedeniyle son jeolojik çağ olan Holosen'den sonra gelen yeni bir jeolojik çağı ifade eden bir terim olarak önerilmiştir (Crutzen ve Stoermer 2000, 17). Bu önerinin ardında ekolojik tahribatlara ilişkin insan sorumluluğunun altını çizmenin yanı sıra bu sorumluluğun ekosistemi koruyacak küresel stratejilerin de bir an önce hayata geçirilmesiydi. İnsanı doğada bir tür ve kolektif eyleyici güç olarak konumlamak gibi bir hedefi vardı. Ve antroposen çağı tanımı benimsendi. Ancak terim aynı zamanda sorunun öznesini muğlaklaştırdı̆̆ı ve belirsizleştirdiği için sosyal bilimciler tarafından eleştirilmektedir.

${ }^{10}$ Jason W. Moore, kapitalosen yani "sermaye çă̆ı” kavramının ilk kez radikal ekonomist David Ruccio tarafindan kullanılmaya başladığını, 2012'ye kadar Haraway tarafından da kullanıldığını belirtmektedir. Moore, kapitalosen teriminin ardında kapitalizmin yalnızca bir ekonomik ve sosyal bir sistem olmadı̆̆ı, aynı zamanda doğayı bir örgütleme yolu olduğuna ilişkin tezler yattığını ifade eder (Moore 2016, 6) Moore kapitalosen dışında anthroposcene, cconocene, technocene, misanthropocene ve manthropecene gibi antroposen'e alternatif ve eleştirel tanımlamaların yapıldı̆̆ını ancak kapitalosenin dünya ekolojisi ve tarihindeki temel dönüşüm ve örüntüleri yakalayan bir kavram olduğunu belirtmektedir.

${ }^{11}$ H.P. Lovecraft'ın insanların henüz olmadığı bir dünyada var olan yaratık ve canlıları içeren hikâye hikayesi Türkçe'de de "Cthulhu'nun Çağrısı” adıyla farklı yayınevleri tarafindan basılmıştır.

${ }^{12}$ Kuşkusuz bu dönüşüm pandemi ile birlikte gerçekleşmedi. Pandemi bu dolayımların yaygınlığını ve yoğunluğunu arttırdı. Yurttaşlık puanlamaları, finansal işlemleri ve düşük tutarlı kredi ve harcama limiti veren uygulamalar ile yoksulların"avucuna taşıyan" fintek (finansal teknoloji) uygulamaları bu türden teknoloji-yapay zeka ve kişisel veri kullanımının sınıfsal, etnik, toplumsal cinsiyet temelli ayrışmalar ve gözetim biçimleri bakımından tüm bu insan-teknoloji dolayımlarını adalet perspektifi ile yeniden düşünmek ve Haraway'ın terminolojisi ile kullanacak olursak "yeni hikayeler anlatmak" için sorumluluk almamız gerekiyor.

\section{Kaynakça}

Bora, Aksu. "Romantik bir Ütopya olarak Siborg”, Ütopyalar. Politikayla Arzunun Kesiştiği Yer (İstanbul: İletişim Yayınlar1, 2018): 199-206.

Bozok, Nihan. “Herkesle ve Kimsesiz, Türler Arasında ve Kökensiz Siborg: Donna Haraway’ın Düşüncesinde Feminist Bir Beden Politikasının Imkânları” ViraVerita E-Dergi 9 (2019): 128-148.

Braidotti, Rosi. A theoretical framework for the critical posthumanities. Theory, Culture \& Society, 36.6 (2018): 31-61.

Christov-Bakargiev, C. “Tuzlu Su: Düşünce Biçimleri Üzerine Bir Teori”, 14. İstanbul Bienali Kataloğu, Çev. Savaş Kılıç. (İstanbul, Yapı Kredi Yayınları, 2015): XXXIV.

Collin, F. ve Kaufer, I. Feminist Güzergah (Ankara: Dipnot Yayınları, 2015)

Cook, Peta S. "The Modernistic Posthuman Prophecy of Donna Haraway", Social Change in the 21st Century Conference (Centre for Social Change Research Queensland University of Technology 29 October 2004). 
https://eprints.qut.edu.au/646/1/cook peta.pdf (11 Ocak 2020 tarihinde erişildi).

Crutzen, P. J., \& Stoermer, E. F. “The Anthropocene” Global change newsletter, 41, (2000).

Ferwerda, S. M. Narrating the Anthropocene. Threading Contemporary Feminist Theory and Fiction in a HumanDominated World (Master's thesis), MA Gender and Ethnicity, Department of Media and Culture Studies (Utrecht University, 2016).

Gane, Nicholas. When we have never been human, what is to be done? Interview with Donna Haraway. In Theory, Culture \& Society 23, 7-8 (2006): 135-158.

Goodeve, Thyrza Nichols. Tıpkı Bir Yaprak Gibi Donna J. Haraway ile Söyleşi , Çev. Aksu Bora, (İstanbul: İletişim Yayınlar1, 2020)

Haraway, Donna. "Manifesto for Cyborgs: Science, Technology and Socialist Feminisn in the 1980s" Socialist Review 80 (1985): 65-108.

Haraway, Donna. Introduction: A kinship of feminist figurations. The Haraway Reader, 2004): 1-6.

Haraway, Donna "Siborg Manifestosu: Yirminci Yüzyılın Sonlarında Bilim, Teknoloji ve Sosyalist Feminizm”, 45-90. Başka Yer, Metis Seçkileri Donna J. Haraway (İstanbul: Metis Yayınları, 2010).

Haraway, Donna. "SF: Science Fiction, Speculative Fabulation, String Figures, So Far”, Ada A Journal of Gender, New Media \& Technology. 3 (2013). https://adanewmedia.org/2013/11/issue3-haraway/ (25 Temmuz 2019 tarihinde erişisildi)

Haraway, Donna “Anthropocene, Capitalocene, Plantationocene, Chthulucene: Making Kin.” Environmental” Humanities 6 (2015): 159-65.

Haraway, Donna. Staying with the trouble: Making kin in the Chthulucene (Durham, NC: Duke University Press, 2016).

Haraway, D. "The Camille Stories: Children of Compost", Staying with the trouble: Making kin in the Chthulucene (Durham, NC: Duke University Press, 2016a): 134-168

Miah, A. A Critical History of Posthumanism. In: Gordijn, B./ Chadwick, R. (Ed.): Medical Enhancement and Posthumanity. (Springer, New York, 2008).

Moore, Jason W. "Introduction”, Der. Jason W. Moore, Anthropocene or Capitalocene? Nature, History, and the Crisis of Capitalism (PM Press, 2016) 